\title{
Histamine and Histidine Decarboxylase Are Correlated with Mucosal Repair in Rat Small Intestine after Ischemia-Reperfusion
}

\author{
Kazuma Fujimoto, * Ikuo Imamura, ${ }^{\ddagger}$ D. Neil Granger, ${ }^{\star}$ Hiroshi Wada, ${ }^{*}$ Toshiie Sakata, ${ }^{5}$ and Patrick Tso* \\ ${ }^{*}$ Department of Physiology, Louisiana State University Medical Center at Shreveport, Shreveport, Louisiana $71130 ;{ }^{\ddagger}$ Department of \\ Pharmacology II, Faculty of Medicine, Osaka University, Osaka 565, Japan; and ${ }^{\S}$ Department of Internal Medicine I, \\ Faculty of Medicine, Kyushu University, Fukuoka 812, Japan
}

\begin{abstract}
The aim of this experiment was to demonstrate whether histamine and histidine decarboxylase (HDC) contribute to mucosal repair in small intestine subjected to ischemia-reperfusion (I/ R). The superior mesenteric artery was occluded for 15 min followed by reperfusion. In jejunal mucosa, histamine content and HDC activity increased after I/R. Histamine output in mesenteric lymph was also elevated after $\mathbf{I} / \mathbf{R}$. These increases in HDC activity, and mucosal and lymph histamine levels were suppressed by pretreatment of $\alpha$-fluoromethylhistidine ( $\alpha$ FMH), a suicide inhibitor of HDC. $\alpha$-FMH also attenuated the increase of ornithine decarboxylase (ODC) activity normally observed after I/R. Transport of dietary lipid into lymph markedly decreased at $24 \mathrm{~h}$ after $I / R$, yet it was restored to normal at $48 \mathrm{~h}$ after I/R. $\alpha$-FMH inhibitor led to a sustained deficit in lipid transport at $48 \mathrm{~h}$ after $\mathrm{I} / \mathrm{R}$. This sustained functional impairment in $\alpha$-FMH treated animals was associated with blunted responses of HDC activity and histamine content to I/R. Our results suggest that histamine and HDC contribute to the restoration in mucosal function observed at $48 \mathrm{~h}$ after $\mathrm{I} / \mathrm{R}$. This response may be related, at least in part, to stimulation of ODC activity by histamine. (J. Clin. Invest. 1992. 89:126133.) Key words: superior mesenteric artery $\bullet$ intestinal lipid absorption • intestinal lymph-fistula rat $\bullet \alpha$-fluoromethylhistidine $\bullet$ ornithine decarboxylase
\end{abstract}

\section{Introduction}

The pharmacological actions of histamine have been extensively characterized and antagonists of the autacoid are widely used in the treatment of disease (1). Although much is known about the importance of histamine in different pathological conditions, there is considerable uncertainty concerning the physiological function of histamine. Recently, it has been demonstrated that histamine may act as a neurotransmitter in the central nervous system (2-4). Synthesis and release of this non-mast cell histamine are controlled by the enzyme histidine decarboxylase (HDC) ${ }^{1}(2-6)$, and the histamine synthe-

\begin{abstract}
Address correspondence to Kazuma Fujimoto, M.D., Ph.D., Department of Physiology, Louisiana State University Medical Center, 1501 Kings Highway, Shreveport, LA 71130. 1991.

Received for publication 16 April 1991 and in revised form 22 July
\end{abstract}

1. Abbreviations used in this paper: DAO, diamine oxidase; $\alpha-\mathrm{FMH}$, $\alpha$-fluoromethylhistidine; HDC, histidine decarboxylase; I/R, ischemiareperfusion; ODC, ornithine decarboxylase; RMCP II, rat mast cell protease II; SMA, superior mesenteric artery.

J. Clin. Invest.

(c) The American Society for Clinical Investigation, Inc.

$0021-9738 / 92 / 01 / 0126 / 08 \$ 2.00$

Volume 89, January 1992, 126-133 sized by this process is rapidly secreted rather than stored in the cell (2-6). The latter characteristic regarding histamine liberation from non-mast cells differs from that observed in mast cells, which store histamine and release the autacoid when the cells are stimulated.

Kahlson and Rosengren $(6,7)$ proposed that newly synthesized histamine in non-mast cells may play an important role in the modulation of tissue growth. HDC activity is markedly stimulated in rapidly proliferating tissues, including fetal tissues from rats and mice (6), tissues undergoing repair (6), mouse skin after application of tumor promoter (8), liver regeneration after hepatectomy $(6,9)$, and in experimental tumors $(7,10)$. Furthermore, exogenous histamine stimulates proliferation of human carcinoma and melanoma cells (11, 12), rat mesentery (13), and rat astroglial cells (14) in culture.

In the small intestine, several physiological actions of histamine have been clearly demonstrated, i.e., the autacoid appears to influence electrolyte transport (15), microvascular permeability (16), and intestinal motility (17). There is also some evidence which indicates that histamine may participate in the process of intestinal proliferation. For example, exogenous histamine administration results in an increase in mitosis of rat jejunal epithelial cells (18). Nonetheless, it remains unclear whether histamine contributes significantly to the intestinal growth and repair that is observed after the small intestine has been injured.

It is well recognized that the small intestine is extremely sensitive to deleterious effects of ischemia-reperfusion (I/R) (19). We have recently demonstrated that occlusion of the superior mesenteric artery (SMA) for 10-20 min, followed by reperfusion, results in a significant reduction of the ability of the small intestine to assimilate dietary lipid at $24 \mathrm{~h}$ after reperfusion (20). However, this decrement in mucosal function is no longer observed at $48 \mathrm{~h}$ after I/R. We hypothesize that HDC and histamine play a pivotal role in tissue repair and restoration of mucosal function observed after I/R and that this beneficial action of histamine is mediated by ornithine decarboxylase (ODC), an enzyme regulates intestinal growth and repair (21-23). To test this hypothesis, we conducted experiments to determine whether $(a)$ mucosal HDC activity and histamine content increase after I/R; $(b)$ the restoration of normal lipid transport at $48 \mathrm{~h}$ after $\mathrm{I} / \mathrm{R}$ is prevented in animals pretreated with $\alpha$-fluoromethylhistidine ( $\alpha$-FMH), a suicide inhibitor of HDC (24); and (c) the increase in mucosal ODC activity, normally elicited by I/R (25), is prevented when HDC activity is inhibited by $\alpha$-FMH.

\section{Methods}

\section{Animals}

$\alpha-F M H$ treatment. Male Sprague-Dawley rats, weighing $250-290 \mathrm{~g}$, were injected i.p. with $\alpha$-FMH dissolved in physiological saline (100 $\mathrm{mg} / \mathrm{kg}$ body $\mathrm{wt}$ ) twice daily for $6 \mathrm{~d}$ before the surgery and also during 
the experiment. Control rats were injected i.p. with physiological saline (vehicle). $\alpha$-FMH was kindly supplied by Dr. J. Kollonitsch, Merck Sharp \& Dohme Research Laboratories.

Surgery. Rats were fasted overnight. Under halothane anesthesia, a laparotomy was performed. The SMA was occluded for $15 \mathrm{~min}$ with a micro-bulldog clamp. At the end of the ischemic period, the clamp was released and a few drops of $2 \%$ lidocaine were applied directly on the SMA to facilitate reperfusion. In the sham-operated controls, the SMA was isolated in a similar fashion but was not occluded. In both groups of animals, the intestinal lymph duct was cannulated and a silicone infusion tube (O.D. $1.6 \mathrm{~mm}$ ) was introduced $\sim 2 \mathrm{~cm}$ down the duodenum through the fundus of the stomach (26).

Postoperative care. Postoperatively, the animals were infused intraduodenally at $3 \mathrm{ml} / \mathrm{h}$ with a saline solution containing $145 \mathrm{mM} \mathrm{NaCl}, 4$ $\mathrm{mM} \mathrm{KCl}$, and $0.28 \mathrm{M}$ glucose. The animals were allowed to recover in restraining cages kept in a temperature-regulated box $\left(30^{\circ} \mathrm{C}\right)(26)$.

\section{Experiment 1: histamine content, HDC activity, and diamine oxidase (DAO) activity in intestinal mucosa after $I / R$}

Procedure. I/R rats receiving vehicle (physiological saline) were sacrificed at $0,1,6,24$, and $48 \mathrm{~h}$ after the ischemic episode. Five or six rats were used in each group. Due to limited availability of $\alpha$-FMH, only one group of $\alpha$-FMH treated I/R rats were studied at $6 \mathrm{~h}$ after I/R. It should be emphasized that even at $6 \mathrm{~h}$ after I/R, neither HDC activity nor histamine content was elevated in the intestinal mucosa of the $\alpha$-FMH treated rats. Under halothane anesthesia, a blood sample obtained from the abdominal aorta was dispensed into precooled tubes containing heparin and then centrifuged to separate the plasma for determination of histamine and DAO activity. Jejunal mucosa was also obtained by scraping with a glass slide over an ice-cold glass plate for determination of histamine content, HDC activity, and DAO activity.

Histamine assay. Mucosal scrapings ( $100 \mathrm{mg}$ wet $\mathrm{wt})$ were homogenized in $300 \mu \mathrm{l}$ of $0.2 \mathrm{M}$ perchloric acid. The homogenates were centrifuged at $10,000 \mathrm{~g}$ for $30 \mathrm{~min}$ at $4^{\circ} \mathrm{C}$. The protein-free supernatant was then used for the determination of histamine content by the HPLC method previous described (27). The lymph and plasma samples were also treated with the perchloric acid mixture and the clear supernatant after centrifugation was also used for histamine determination.

$H D C$ assay. Mucosal scrapings ( $100 \mathrm{mg}$ wet wt) were homogenized in $1 \mathrm{ml}$ of $0.1 \mathrm{M}$ PBS (pH 6.8), containing $0.2 \mathrm{mM}$ dithiothreitol, 0.01 $\mathrm{mM}$ pyridoxal $5^{\prime}$ phosphate, $0.01 \mathrm{mM}$ aminoguanidine, $33 \mathrm{mM}$ of polyethylene glycol (mol wt 300) and 0.1 mM PMSF (8). After homogenization and centrifugation $\left(10,000 \mathrm{~g}\right.$ for $30 \mathrm{~min}$ at $\left.4^{\circ} \mathrm{C}\right)$, the sample was dialyzed twice at $4^{\circ} \mathrm{C}$ against $100 \mathrm{vol}$ of PBS. The dialyzed sample $(180 \mu \mathrm{l})$ was then incubated with $20 \mu \mathrm{l}$ of $2.5 \mathrm{mM}$ L-histidine at $37^{\circ} \mathrm{C}$ for $200 \mathrm{~min}$. For the sample blank, the dialyzed sample was incubated with $20 \mu \mathrm{l}$ of $2.5 \mathrm{mM}$ L-histidine and $1 \mathrm{mM} \alpha$-FMH. The reaction was terminated by adding $10 \mu \mathrm{l}$ of $6 \mathrm{M}$ perchloric acid. After brief centrifugation, the content of histamine was measured using HPLC (27). L-Histidine was purified before use. Purification of histidine involved dissolving $20 \mathrm{~g}$ of histidine in $20 \mathrm{ml}$ of $2 \mathrm{~N} \mathrm{NaOH}$. Concentrated $\mathrm{HCl}$ was added to adjust the $\mathrm{pH}$ to 5 , which resulted in the precipitation of histidine. The histidine precipitate was filtered, washed twice with 10 $\mathrm{ml}$ of water, and dried in a desiccator.

$D A O$ assay. To assay DAO activity, $\left[1,4-{ }^{14} \mathrm{C}\right]$ putrescine (Amersham Corp., Arlington Heights, IL) was used as a substrate (28). Mucosal scrapings (200 mg) were homogenized in $3 \mathrm{ml}$ of $0.2 \mathrm{M} \mathrm{PBS} \mathrm{(pH}$ 7.6), and were centrifuged at $48,000 \mathrm{~g}$ for $30 \mathrm{~min}$. $\left[{ }^{14} \mathrm{C}\right]$ Putrescine was mixed with unlabeled putrescine to yield a specific activity of 0.22 $\mu \mathrm{Ci} / \mu \mathrm{mol}$ and this was then mixed with PBS to form $4.5 \mathrm{mM}$ putrescine solution. $50 \mu \mathrm{l}$ of the putrescine solution and $200 \mu \mathrm{l}$ of the supernatant of the mucosal homogenate were mixed and incubated at $37^{\circ} \mathrm{C}$ for $30 \mathrm{~min}$, and the reaction was terminated by addition of $200 \mu \mathrm{l}$ of $1.7 \mathrm{M}$ perchloric acid. After adding $1 \mathrm{ml}$ of $1 \mathrm{~N} \mathrm{NaOH}$, the incubation mixture was extracted with $6 \mathrm{ml}$ toluene including $0.35 \%$ 2,5-diphenyloxazole. The toluene phase was then counted for $10 \mathrm{~min}$ in a liquid scintil- lation spectrometer (model 1209 Rackbeta; LKB Instruments, Inc., Gaithersburg, MD).

\section{Experiment 2: histamine output, DAO activity, and rat mast-cell protease II (RMCP II) output in intestinal lymph after $I / R$}

Procedure. Intestinal lymph samples were collected in lymph-fistula rats at $1,3,6,24$, and $48 \mathrm{~h}$ after the surgery to measure histamine and RMCP II output, and DAO activity in intestinal lymph. Three groups of animals were studied: sham-operated controls pretreated with vehicle, $\mathrm{I} / \mathrm{R}$ rats pretreated with vehicle, and $\mathrm{I} / \mathrm{R}$ rats pretreated with $\alpha$ FMH. Five rats were tested in each group.

Rat mucosal protease II (RMCP II) assay. Lymphatic RMCP II concentration was measured by ELISA technique as previously described in detail (29). This assay was kindly performed by Dr. Dean A. Befus, the University of Calgary.

\section{Experiment 3: effects of $\alpha-F M H$ on transport of dietary lipid after $I / R$}

Procedure. Intestinal lymph-fistula rats were studied at 24 or $48 \mathrm{~h}$ after surgery. Eight groups of four or five animals were studied. At 24 or $48 \mathrm{~h}$ after surgery, the following four groups of rats were studied: $(a)$ shamoperated rats pretreated with vehicle, $(b) \mathrm{I} / \mathrm{R}$ rats pretreated with vehicle, $(c)$ sham-operated rats pretreated with $\alpha$-FMH, and $(d)$ I/R rats pretreated with $\alpha$-FMH.

Each rat was infused with a lipid emulsion containing $0.708 \mathrm{~g}$ of triolein $\left(800 \mu \mathrm{mol}\right.$ of triolein), $1 \mu \mathrm{Ci}$ of glycerol tri[ $\left[9,10(n){ }^{3} \mathrm{H}\right]$ oleate, $68 \mathrm{mg}$ of egg phosphatidylcholine $(78 \mu \mathrm{mol})$ and $570 \mu \mathrm{mol}$ of sodium taurocholate in $30 \mathrm{ml}$ of PBS (pH 6.4). The dose of triolein used was twice the dose we have used in our previous study $(20,26)$. The rationale for choosing a higher dose of triolein is as follows. Most of the dietary lipid was absorbed by the upper quarter of the small intestine. Thus to ascertain that the defect in lipid transport into lymph was not limited only to the first quarter of the small intestine, we have chosen to infuse twice the normal dose of triolein used in the other studies $(20$, 26). The PBS contained $6.75 \mathrm{mM} \mathrm{Na}_{2} \mathrm{HPO}_{4}, 16.5 \mathrm{mM} \mathrm{NaH}_{2} \mathrm{PO}_{4}, 115$ $\mathrm{mM} \mathrm{NaCl}$, and $5 \mathrm{mM} \mathrm{KCl}$. The emulsion was infused intraduodenally at $3 \mathrm{ml} / \mathrm{h}$ for $8 \mathrm{~h}$.

Preparation of emulsion. On the day of the experiment, appropriate amounts of stock lipid solutions were mixed. Solvent was evaporated under a stream of nitrogen. Sodium taurocholate, dissolved in PBS, was then added to make up to the required lipid concentration, and the mixture was sonicated. Samples of the infusate were analyzed for triglyceride content and radioactivity at the beginning and end of infusion (reproducibility $\pm 5 \%$ ).

Collection of lymph, luminal, and mucosal samples. Lymph was collected into precooled tubes for $1 \mathrm{~h}$ before the lipid infusion was begun. This sample represented the fasting lymph sample. Additional lymph samples were collected at 2, 4, 5, 6, 7, and $8 \mathrm{~h}$ after the beginning of lipid infusion. At the end of lipid infusion, the animal was anesthetized and the portal blood was collected. The rats were killed by exsanguination, the liver was removed, and the stomach and colon were excised separately after tying both ends with care to prevent leakage of luminal contents. The small intestine was divided into four segments of equal length. The luminal contents of each segment were rinsed with three washes of $10 \mathrm{mM}$ sodium taurocholate. The radioactive lipid recovered in the luminal contents represented the lipid that was infused but not yet absorbed by the small intestine. The lipid from each intestinal segment and the liver was then extracted (26). The lipid recovered from the intestinal wall represented the lipid absorbed, but not yet transported, by the small intestine. Radioactivity was measured in an aqueous miscible scintillant (Poly-Flour; Packard Instrument Co., Downers Grove, IL). The samples were counted for $10 \mathrm{~min}$ in a liquid scintillation spectrometer (model 1209 Rackbeta; LKB Instruments, Inc.). Samples were collected for quenching by reference to a series of ${ }^{3} \mathrm{H}$ standards that had been progressively quenched. 
Experiment 4: effects of $\alpha-F M H$ on ornithine decarboxylase activity after $I / R$

Procedure. Ornithine decarboxylase (ODC) activity in rat jejunal mucosa was measured in rats pretreated either with vehicle or $\alpha-\mathrm{FMH}$. The ODC activity was measured both before and at $6 \mathrm{~h}$ after I/R. Five rats were studied in each group.

$O D C$ assay. ODC activity was assayed by a radiometric technique in which the amount of ${ }^{14} \mathrm{CO}_{2}$ liberated from levo- $\left[1-{ }^{14} \mathrm{C}\right]$ ornithine $(52.3 \mathrm{mCi} / \mathrm{mmol}$; New England Nuclear, Boston, MA) was measured (22). Mucosal scrapings from jejunum ( $200 \mathrm{mg}$ wet $\mathrm{wt}$ ) were placed in 2 $\mathrm{ml}$ of $0.1 \mathrm{M}$ Tris buffer ( $\mathrm{pH}$ 7.4), containing $1 \mathrm{mM}$ EDTA, $50 \mu \mathrm{M}$ pyridoxal $5^{\prime}$ phosphate, and $5 \mathrm{mM}$ dithiothreitol. The tissues were homogenized and centrifuged at $30,000 \mathrm{~g}$ for $30 \mathrm{~min}$. Protein content was
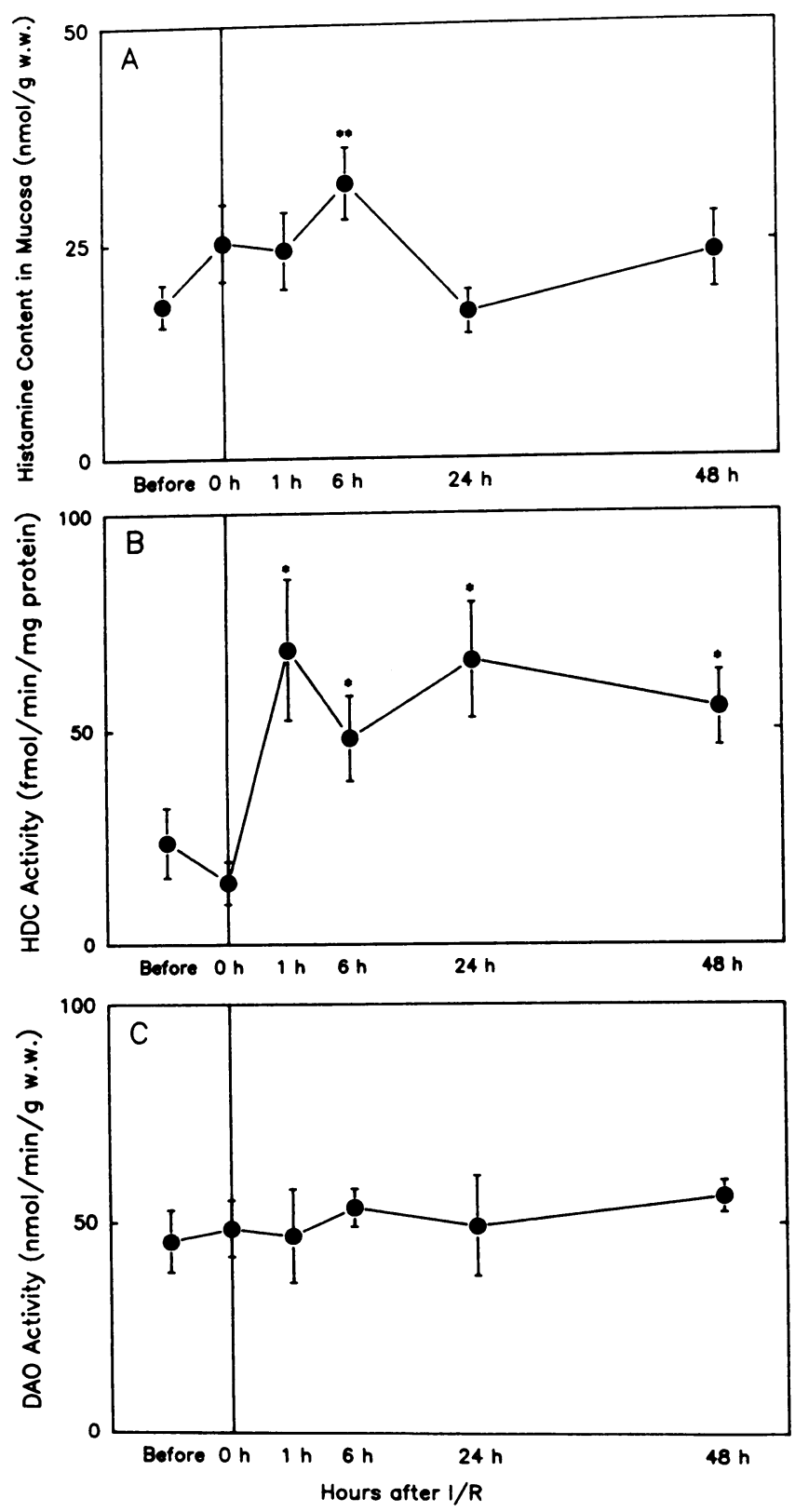

Figure 1. Histamine content, histidine decarboxylase (HDC) activity and diamine oxidase (DAO) activity in jejunal mucosa after ischemia-reperfusion $(\mathrm{I} / \mathrm{R})$ in rats pretreated with vehicle. $(A)$ Histamine content. $(B)$ HDC activity. $(C)$ DAO activity. Values are expressed as mean \pm SE. w.w., wet weight. ${ }^{*} P<0.05,{ }^{* *} P<0.01$, compared to the values before $I / R$. determined, and a $200-\mu \mathrm{l}$ aliquot of the supernatant was incubated in stoppered vials in the presence of $3.5 \mathrm{nmol}$ of levo- $\left[1-{ }^{14} \mathrm{C}\right]$ ornithine for $15 \mathrm{~min}$ at $37^{\circ} \mathrm{C}$. The ${ }^{14} \mathrm{CO}_{2}$ liberated by the decarboxylation of ornithine was trapped on a piece of filter paper impregnated with $20 \mu \mathrm{l}$ of $2 \mathrm{~N} \mathrm{NaOH}$, which was suspended above the reaction mixture. The reaction was terminated by the addition of $0.3 \mathrm{ml}$ of $10 \%$ TCA. Radioactivity of the ${ }^{14} \mathrm{CO}_{2}$ trapped in the filter paper was measured in an aqueous miscible scintillant (Poly-Flour; Packard Instrument Co.).

\section{Statistics}

Results are expressed as means \pm SE. Data were evaluated by an analysis of variance with replications in which orthogonal decomposition for linear comparison was carried out. Multiple comparisons were carried out with the method of least significant difference (30). Differences were considered significant if the probability of the difference occurring by change was less than 5 in $100(P<0.05)$.

\section{Results}

Experiment 1: effects of $I / R$ on histamine content, $H D C$ activity, and DAO activity in intestinal mucosa

Histamine content in rat jejunal mucosa (pretreated with vehicle) after I/R is shown in Fig. $1 \mathrm{~A}$. Histamine content did not change up to $1 \mathrm{~h}$ after $\mathrm{I} / \mathrm{R}$. Mucosal histamine in jejunum increased significantly $6 \mathrm{~h}$ after $\mathrm{I} / \mathrm{R}$ as compared to the value observed before $\mathrm{I} / \mathrm{R}(P<0.01)$. This increase was not observed in sham-operated rats even at $6 \mathrm{~h}$ after surgery $(22.0 \pm 2.1 \mathrm{nmol} /$ $\mathrm{g}$ wet $\mathrm{wt}$ of mucosa). The increase in mucosal histamine content observed in I/R rats returned to preischemic values at 24 and $48 \mathrm{~h}$ after $\mathrm{I} / \mathrm{R}$. In contrast to mucosal histamine in jejunum, plasma histamine level did not change significantly after ischemia (data not presented).

HDC activity and DAO activity in the jejunum of rats pretreated with vehicle are shown in Fig. $1, B$ and $C$, respectively. HDC activity did not increase immediately after ischemia but was markedly elevated (three times) $1 \mathrm{~h}$ after $\mathrm{I} / \mathrm{R}(P<0.05)$ when compared with the preischemic values. HDC activity was elevated throughout the 48-h period after the ischemic episode $(P<0.05$ for each). The HDC activity was not elevated in sham-operated rats at $6 \mathrm{~h}$ after surgery $(24.1 \pm 5.1 \mathrm{fmol}$ histamine formed/min per mg mucosal protein). DAO activity in the intestinal mucosa did not change significantly before and after the ischemic episode (Fig. 1C). DAO activity in plasma also did not change either before or after ischemia (data not presented).

The effects of $\alpha$-FMH on histamine content and HDC activity in the mucosa of the $I / R$ rats are summarized in Table I. In

Table I. HDC Activity and Histamine Content in Jejunal Mucosa before and $6 h$ after $I / R$ in Rats Pretreated for $6 d$ with $\alpha-F M H$

\begin{tabular}{lcr}
\hline & Before $\mathrm{I} / \mathrm{R}$ & $6 \mathrm{~h}$ after $\mathrm{I} / \mathrm{R}$ \\
\hline HDC activity $($ fmol/min/mg protein) & & \\
$\quad$ Pretreated with vehicle & $24.0 \pm 7.9$ & $50.6 \pm 8.6^{*}$ \\
Pretreated with $\alpha$-FMH & $4.8 \pm 1.7^{*}$ & $0.9 \pm 0.6^{*}$ \\
Histamine content $($ nmol/g wet $w t)$ & & \\
Pretreated with vehicle & $17.9 \pm 2.5$ & $31.8 \pm 4.2^{\ddagger}$ \\
Pretreated with $\alpha$-FMH & $11.3 \pm 2.0^{*}$ & $10.4 \pm 0.8^{*}$
\end{tabular}

Data were shown as mean \pm SE.

${ }^{*} P<0.05$, compared to the values of vehicle controls.

${ }^{\ddagger} P<0.05$, compared to the values before $\mathrm{I} / \mathrm{R}$. 


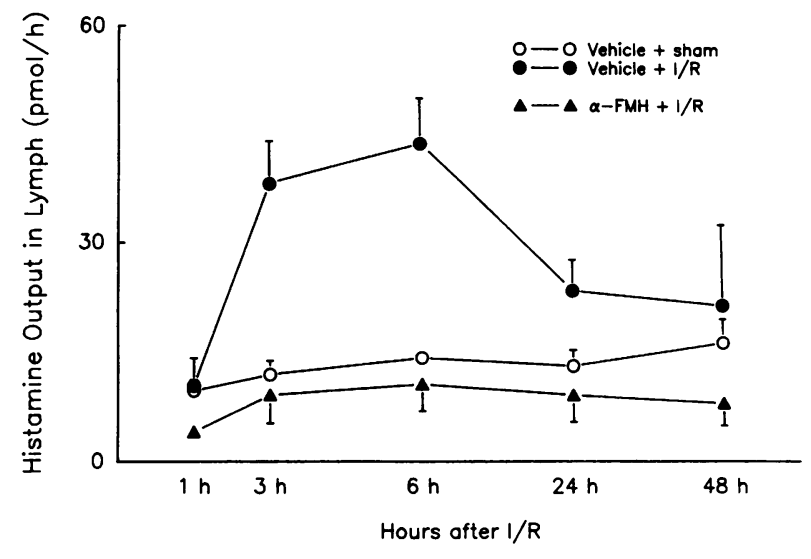

Figure 2. Histamine output in intestinal lymph after ischemia-reperfusion (I/R). Values are expressed as mean \pm SE. $\alpha$-FMH, $\alpha$-fluoromethylhistidine. Histamine output in rats treated with vehicle increased at $3 \mathrm{~h}$ after $\mathrm{I} / \mathrm{R}$ compared to sham-operated rats $(P<0.01)$ and this increase was completely suppressed in rats treated with $\alpha$ FMH $(P<0.01)$.

I/R rats pretreated with vehicle, mucosal HDC activity, and histamine content increased significantly after $\mathrm{I} / \mathrm{R}(P<0.05$ for each). After treatment with $\alpha$-FMH i.p. twice daily for $6 \mathrm{~d}$, both HDC activity and histamine content decreased significantly compared to rats treated with vehicle $(P<0.05$ for each) and both variables failed to increase in response to I/R. DAO activity did not change after $\alpha$-FMH treatment (data not presented).

Experiment 2: effect of $I / R$ on lymphatic histamine, $D A O$, and RMCP II output

Fig. 2 demonstrates that the histamine output in lymph of sham controls treated with vehicle remained relatively constant at $\sim 10 \mathrm{pmol} / \mathrm{h}$ during the entire $48 \mathrm{~h}$ period after the surgery. In contrast, lymphatic histamine output increased markedly at 3 and $6 \mathrm{~h}$ after I/R. When compared with the sham-operated controls, the differences are significant up to 24 $\mathrm{h}$ after I/R $(P<0.01$ for each), but returned to the sham-operated control level at $48 \mathrm{~h}$ after I/R. $\alpha$-FMH pretreatment totally abolished the increase in lymphatic histamine output in $I / R$ rats $(P<0.01$ compared to $\mathrm{I} / \mathrm{R}$ rats treated with vehicle). In contrast to HDC, both I/R and $\alpha$-FMH had no effect on DAO activity in mesenteric lymph (Table II).

One potential source of the increase in lymphatic histamine was from mucosal mast cell degranulation. A specific protease marker for the mucosal mast cell is $\operatorname{RMCP}$ II $(29,31,32)$. The concentration of RMCP II in lymph was measured by ELISA.
As shown in Table III, the RMCP II output in mesenteric lymph did not change significantly in the vehicle pretreated or the $\alpha$-FMH pretreated animals after I/R. Thus, the increase in lymphatic histamine after $I / R$ was not due to the degranulation of the mucosal mast cells. The RMCP II concentration in systemic blood also remain unchanged after I/R (data not presented).

\section{Experiment 3: effect of $\alpha-F M H$ on lymphatic transport of dietary lipid after $I / R$}

Lipid output in mesenteric lymph. Because the lymph flow rates were not different between four tested groups at $24 \mathrm{~h}$ after surgery, the data is not presented. All four groups had comparable lymph flow rate during fasting $2-2.5 \mathrm{ml} / \mathrm{h}$. After lipid infusion in all four groups, lymph flow rates increased and reached a steady output of $\sim 3.5 \mathrm{ml} / \mathrm{h}$ during the $6-8 \mathrm{~h}$ of lipid infusion. The lymphatic radioactive lipid output (expressed as percent of radioactive lipid infused per hour) at $24 \mathrm{~h}$ after I/R is shown in Fig. 3. The lymphatic radioactive lipid output in the sham-operated controls (pretreated with vehicle or $\alpha$-FMH) increased as a result of lipid infusion and reached a steady output during the sixth, seventh, and eighth $\mathrm{h}$ of $\sim 75 \%$ of the hourly infused radioactive lipid. As expected, the lymphatic radioactive lipid output of $I / R$ animals (pretreated with vehicle) was markedly depressed as compared to the sham-operated controls $(P<0.01)$. Pretreatment with $\alpha$-FMH did not lead to a further depression in lymphatic radioactive lipid transport in $\mathrm{I} / \mathrm{R}$ animals yet the output in this group was significantly lower than that observed in sham-operated controls $(P<0.01)$. These results indicate that $\alpha$-FMH per se had no effect on lipid output at $24 \mathrm{~h}$ after $\mathrm{I} / \mathrm{R}$.

Fig. 4 summarizes the lymphatic radioactive lipid output data observed at $48 \mathrm{~h}$ after surgery. The lymph flow responses after lipid feeding were not different among the four groups of rats (data not shown). Lymph lipid output increased after fat feeding in both groups of sham-operated controls (with vehicle or with $\alpha-\mathrm{FMH}$ ) and reached a steady output of $\sim 75 \%$ of the radioactive lipid infused hourly. In $I / R$ rats pretreated with vehicle, lymphatic radioactive lipid output was nearly identical to the outputs observed in the two groups of sham-operated controls. This data is consistent with our previous finding that the depressed lymphatic radioactive lipid transport induced by $\mathrm{I} / \mathrm{R}$ is restored to normal at $48 \mathrm{~h}(20)$. This restoration of normal lymphatic lipid transport in I/R animals was not observed in animals pretreated with $\alpha$-FMH. Consequently, the lymphatic radioactive lipid output was significantly lower in $\mathrm{I} / \mathrm{R}$ rats receiving $\alpha$-FMH than the other three groups and the differences were statistically significant for all time points $(P$ $<0.01$ ). These data clearly indicate the importance of HDC

Table II. DAO Activity (Nanomoles Putrescine Metabolized per Minute per Hourly Lymph Output) in Mesenteric Lymph after I/R

\begin{tabular}{|c|c|c|c|c|c|}
\hline & \multicolumn{5}{|c|}{ Hours after surgery } \\
\hline & 1 & 3 & 6 & 24 & 48 \\
\hline Vehicle + sham & $2.29 \pm 0.46$ & $2.53 \pm 0.49$ & $2.45 \pm 0.83$ & $2.05 \pm 0.32$ & $2.45 \pm 0.55$ \\
\hline Vehicle + I/R & $2.18 \pm 2.84$ & $2.71 \pm 0.74$ & $2.15 \pm 0.32$ & $2.69 \pm 0.51$ & $2.26 \pm 0.39$ \\
\hline$\alpha-\mathrm{FMH}+\mathrm{I} / \mathrm{R}$ & $2.64 \pm 0.46$ & $2.32 \pm 0.41$ & $2.10 \pm 0.33$ & $2.47 \pm 0.73$ & $2.49 \pm 0.48$ \\
\hline
\end{tabular}

Data were shown as mean $\pm \mathrm{SE}$. 
Table III. RMCP II Output in Mesenteric Lymph after I/R

\begin{tabular}{llll}
\hline & \multicolumn{3}{c}{ Hours after surgery } \\
\cline { 2 - 4 } & \multicolumn{1}{c}{1} & \multicolumn{1}{c}{6} \\
\hline & \multicolumn{3}{c}{$n g / h$} \\
Vehicle + sham & $328.0 \pm 120.3$ & $312.0 \pm 100.3$ & $320.7 \pm 49.3$ \\
Vehicle + I/R & $334.0 \pm 71.7$ & $345.7 \pm 96.6$ & $311.0 \pm 111.4$ \\
$\alpha-$ FMH + I/R & $274.0 \pm 81.3$ & $337.8 \pm 28.0$ & $326.3 \pm 95.8$ \\
& & & \\
\hline
\end{tabular}

Data were shown as mean \pm SE.

and histamine in the restoration of normal lymphatic lipid transport after $\mathrm{I} / \mathrm{R}$ induced injury.

Distribution of radioactive lipid in lymph, lumen, and $m u$ cosa. Fig. 5 summarizes the radioactive lipid recovery data from rats studied at 24 and $48 \mathrm{~h}$ after surgery. Recovery of radioactive lipid is expressed as percent of total radioactive lipid infused. As shown in Fig. 5, there was a significant reduction in the recovery of radioactive lipid in lymph of both vehicle and $\alpha$-FMH pretreated I/R rats when compared to shamoperated controls at $24 \mathrm{~h}$ after the surgery $(P<0.01$ for both comparisons). A significant difference in lymphatic radioactive lipid recovery was not observed between the two I/R groups. Lymphatic radioactive lipid output was restored to normal in I/R rats pretreated with vehicle at $48 \mathrm{~h}$ after reperfusion (Fig. 5 ). However, pretreatment with $\alpha$-FMH prevented the restoration of lymphatic radioactive lipid output normally observed at $48 \mathrm{~h}$ after $\mathrm{I} / \mathrm{R}$.

No significant differences in luminal and mucosal radioactive lipid recoveries were observed among the different groups studied both at 24 and $48 \mathrm{~h}$ after surgery, indicating that the digestion and uptake of dietary lipid were not different between these experimental groups. However, it should be noted that the amount of radioactive lipid recovered in the mucosa of the

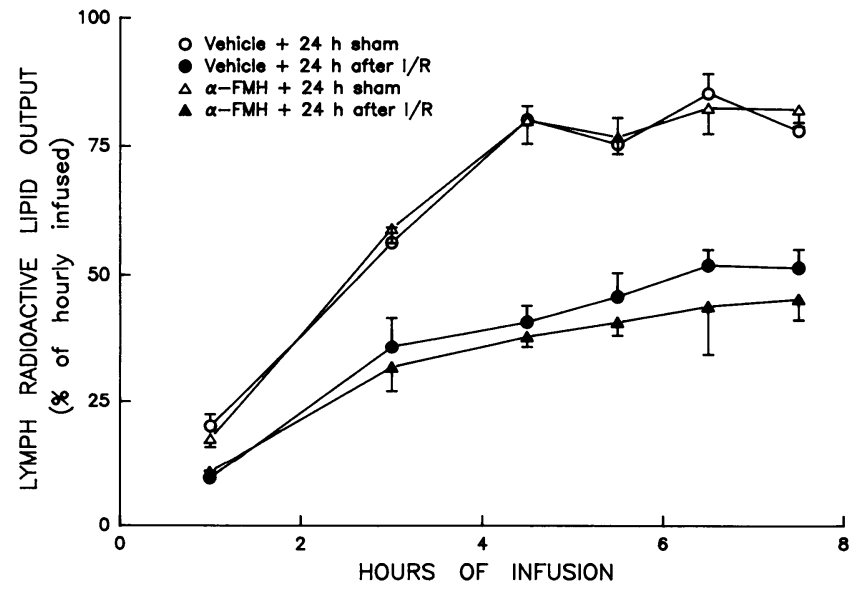

Figure 3. Lymphatic radioactive lipid output expressed as a percentage of the radioactivity infused per $h$ in rats at $24 \mathrm{~h}$ after surgery. Values are expressed as mean \pm SE. I/R, ischemia reperfusion. $\alpha$ FMH, $\alpha$-fluoromethylhistidine. Lipid output in both groups of rats treated with vehicle only and $\alpha$-FMH was suppressed at $24 \mathrm{~h}$ after I/R compared to sham-operated rats $(P<0.01)$, but there were no significant differences between these two groups.

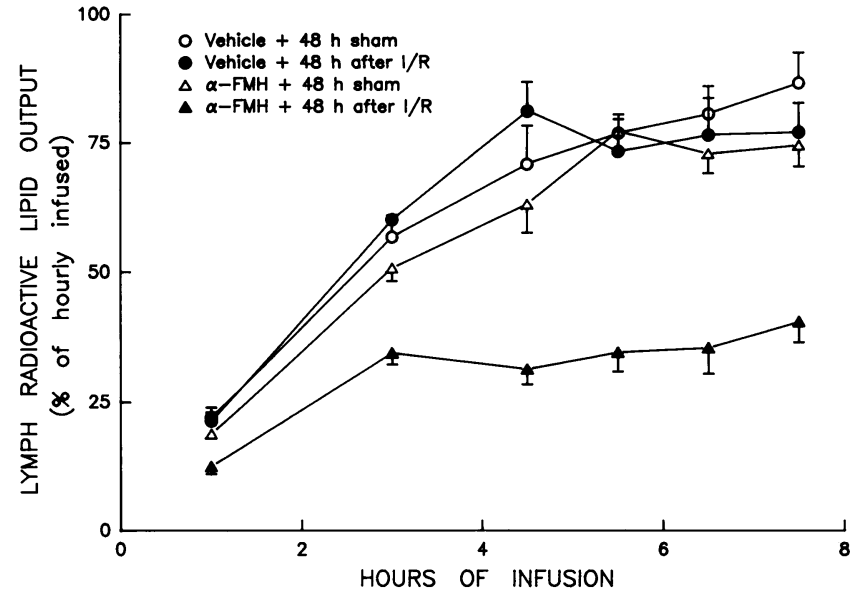

Figure 4. Lymphatic radioactive lipid output expressed as a percentage of the radioactive lipid infused per $h$ in rats at $48 \mathrm{~h}$ after surgery. Values are expressed as mean $\pm \mathrm{SE}$. I/R, ischemia reperfusion. $\alpha$ FMH, $\alpha$-fluoromethylhistidine. The restoration of lipid output in lymph, which was observed in rats treated with vehicle at $48 \mathrm{~h}$ after $\mathrm{I} / \mathrm{R}$, was attenuated markedly in $\alpha$-FMH-treated rats $(P<0.01)$.

various groups was $\sim 25 \%$, which is twice that observed in our previous study (20). This difference resulted from the higher (twice) dose of radioactive triolein used in the present study. The higher dose of triolein was used to determine if decrement in lymphatic lipid transport induced after $I / R$ was limited only to the proximal quarter of the small intestine. Unlike in previous studies (20), in which mucosal lipid was largely confined to the proximal quarter of small intestine, mucosal radioactive lipid in the present study was recovered in both the first and second quarters of small intestine in all groups (data not presented). The distribution of luminal radioactive lipid was simi-

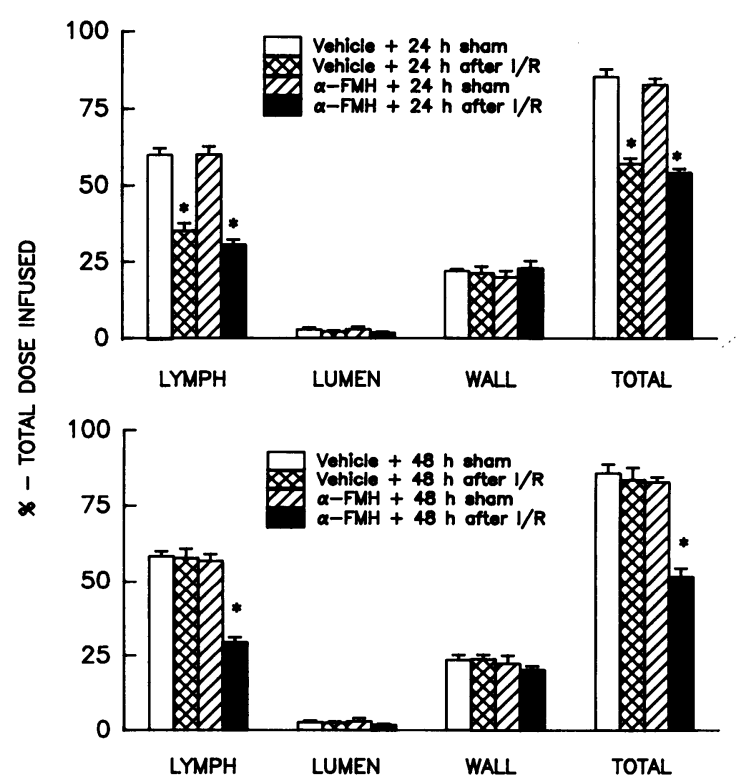

Figure 5. Recovery of radioactive lipid in lymph, intestinal wall, lumen, and the sum of these three (total) at $24 \mathrm{~h}$ or $48 \mathrm{~h}$ after surgery. Values are expressed as mean $\pm \mathrm{SE}$. I/R, ischemia reperfusion. $\alpha$ FMH, $\alpha$-fluoromethylhistidine. ${ }^{*} P<0.01$, compared to the values of sham-operated rats. 
lar in all groups of animals with a pattern similar to the distribution of mucosal radioactive lipid.

Recovery of radioactive lipid in liver and portal blood. In a previous study (20), we demonstrated that there was increased portal transport of the radioactive lipid infused in $\mathrm{I} / \mathrm{R}$ animals at $24 \mathrm{~h}$, but not $48 \mathrm{~h}$, after I/R as compared to the sham-operated controls. We also determined the radioactive lipid appearing in liver. As shown in Table IV, radioactive lipid recovery in liver and portal blood of $\mathrm{I} / \mathrm{R}$ animals (receiving either vehicle or $\alpha-\mathrm{FMH}$ ) was markedly elevated as compared to the $24-\mathrm{h}$ sham-operated controls and the differences were statistically significant ( $P<0.05$ for both comparisons). This elevated portal transport of radioactive fat and the increased hepatic radioactive fat content were restored to sham-operated control levels at $48 \mathrm{~h}$ after ischemia in the I/R animals pretreated with vehicle. In contrast, pretreatment with $\alpha$-FMH prevented the reductions in portal radioactive fat transport and hepatic radioactive fat content observed at $48 \mathrm{~h}$ after ischemia. Consequently, both portal radioactive fat transport and hepatic radioactive fat content were significantly higher in the I/R $+\alpha$-FMH animals than in the other three groups at $48 \mathrm{~h}$ after surgery $(P<0.05$ for all the three comparisons).

\section{Experiment 4: effects of $\alpha-F M H$ on ornithine} decarboxylase activity after $I / R$

ODC activity in jejunal mucosa $6 \mathrm{~h}$ after $\mathrm{I} / \mathrm{R}$ is shown in Table V. $6 \mathrm{~h}$ was chosen because we previously found that ODC activity in the mucosa reached the highest level at $6 \mathrm{~h}$ after I/R (25). Before I/R, ODC activity did not differ significantly between rats treated with either vehicle or $\alpha$-FMH. ODC activity increased markedly in rats pretreated with vehicle and was 20fold higher at $6 \mathrm{~h}$ after $\mathrm{I} / \mathrm{R}$ than the level observed in rats before I/R $(P<0.01)$. This elevation of jejunal mucosal ODC activity was attenuated by pretreatment with $\alpha$-FMH and the elevation of mucosal ODC activity in this group was significantly less than in I/R animals pretreated with vehicle $(P<0.01)$. However, mucosal ODC activity in $I / R$ animals pretreated with $\alpha$-FMH was still significantly higher than the level observed before the ischemic insult $(P<0.05)$. Thus, our results indicate that while $\alpha$-FMH attenuates the elevation of mucosal ODC induced by $\mathrm{I} / \mathrm{R}$, it did not completely abolish this response.

Table IV. Percent Recovery of Labeled Triolein from Liver, and Portal Blood Flow in Rats at 24 or $48 \mathrm{~h}$ after $I / R$

\begin{tabular}{ccc}
\hline & $\begin{array}{c}\text { Liver } \\
\text { (\% lipid infused) }\end{array}$ & $\begin{array}{c}\text { Portal blood } \\
\text { (\% lipid infused/ml of plasma) }\end{array}$ \\
\hline 24 h after surgery & & \\
Vehicle + sham & $0.27 \pm 0.06$ & $0.039 \pm 0.008$ \\
Vehicle + I/R & $1.31 \pm 0.40^{*}$ & $0.103 \pm 0.024^{*}$ \\
$\alpha-$ FMH + sham & $0.22 \pm 0.06$ & $0.033 \pm 0.006$ \\
$\alpha$-FMH + I/R & $1.48 \pm 0.34^{*}$ & $0.093 \pm 0.011^{*}$ \\
48 h after surgery & & \\
Vehicle + sham & $0.30 \pm 0.08$ & $0.038 \pm 0.006$ \\
Vehicle + I/R & $0.19 \pm 0.13$ & $0.044 \pm 0.013$ \\
$\alpha-$ FMH + sham & $0.20 \pm 0.11$ & $0.033 \pm 0.014$ \\
$\alpha-$ FMH + I/R & $1.16 \pm 0.40^{*}$ & $0.119 \pm 0.020^{*}$ \\
\hline
\end{tabular}

Values are expressed as a percent of total radioactive lipid infused, mean \pm SE. $\alpha$-FMH, $\alpha$-fluoromethylhistidine. ${ }^{*} P<0.05$, compared to the vehicle + sham controls.
Table V. Effect of $\alpha-F M H$ on ODC Activity at $6 \mathrm{~h}$ after $I / R$

\begin{tabular}{lcc}
\hline & \multicolumn{2}{c}{ ODC activity } \\
\cline { 2 - 3 } & \multicolumn{1}{c}{ Before I/R } & $6 \mathrm{~h}$ after I/R \\
\hline Treated with $\alpha-\mathrm{FMH}$ & \multicolumn{2}{c}{$\mathrm{CO}_{2}$ pmol/h/mg protein } \\
Treated with vehicle & $7.9 \pm 3.5$ & $32.7 \pm 9.1^{* \S}$ \\
& $5.6 \pm 3.4$ & $140.0 \pm 20.1^{\ddagger}$
\end{tabular}

Data were shown as mean \pm SE. ${ }^{*} P<0.05$ and ${ }^{\ddagger} P<0.01$, compared to the corresponding values before $\mathrm{I} / \mathrm{R} .{ }^{\S} P<0.01$, compared to the values of rats pretreated with vehicle.

\section{Discussion}

The aims of the present experiments were twofold. First, we sought to demonstrate whether mucosal HDC activity and histamine may play a role in the restoration of mucosal function in intestine subjected to I/R. Second, we determined whether any histamine-mediated response to $I / R$ involves the mucosal enzyme, ODC. The results obtained from four separate series of experiments indicate that HDC and histamine contribute significantly to the repair process that is elicited in the first $48 \mathrm{~h}$ after reperfusion of the ischemic bowel. Our findings also indicate that the beneficial action of histamine is mediated, at least in part, by the first rate-limiting enzyme in polyamine biosynthesis, i.e., ODC.

A well-documented source of mucosal histamine is that found in the mast cells residing in the lamina propria of the intestinal mucosa $(33,34)$. Mast cells are known to store histamine and to discharge the autacoid and numerous other biogenic compounds upon activation by immunologic or nonimmunologic stimuli (31-34). Histamine is also synthesized by cells other than mast cells $(6,7)$. Virtually all of mammalian organs studied exhibits some HDC activity, including the gastrointestinal tract (35), however, the identity of the cell that produce non-mast cell histamine in the small intestine has not been clearly established. Nonetheless, it is now well recognized that the histamine produced in the gut mucosa is either rapidly cleared by blood and lymph or it is degraded either by diamine oxidase, an enzyme present in intestinal epithelium $(36,37)$, or by a methylation reaction to form methylhistamine (36). Thus, at any given moment, mucosal histamine content does not necessarily reflect the rate of histamine formation because the quantity of the autacoid is also determined by clearances via blood and lymph and its rate of degradation. A more accurate index of mucosal histamine formation is the activity of HDC, which is the enzyme that leads to the formation of non-mast cell histamine.

One objective of the present study is to determine whether HDC activity and histamine content in rat intestinal mucosa and mesenteric lymph are altered in response to I/R. We observed that mucosal HDC activity was markedly elevated over a 48-h period after a 15-min occlusion of the SMA. This data indicates that $I / R$ results in either an induction of mucosal HDC activity or removal of endogenous factors that act to inhibit basal HDC activity. Either mechanism would result in increase histamine synthesis and consequently increase content of the autacoid in intestinal mucosa. The mucosal histamine data are corroborated by our findings on lymphatic histamine output, which was elevated at $1-3 \mathrm{~h}$ after I/R and it remained elevated for up to $24 \mathrm{~h}$. However, it should be noted 
that mucosal HDC activity was elevated for the entire $48 \mathrm{~h}$ after $\mathrm{I} / \mathrm{R}$, whereas both mucosal histamine content and lymph histamine output returned to preischemic levels within $48 \mathrm{~h}$ after I/R. This apparent discrepancy between mucosal HDC activity and histamine content may be explained by an imbalance between the rates of histamine synthesis and degradation which favors the former during the early period after reperfusion.

Histamine has been implicated in the modulation of tissue growth in a variety of experimental models. The increase in mucosal histamine content, lymph histamine output, and mucosal HDC activity observed in our study would therefore suggest that HDC and histamine play a role in the recovery of mucosal function after I/R. To address this possibility, we employed $\alpha$-FMH, which is a specific suicide inhibitor of HDC. It is well known that this inhibitor decreases histamine synthesis, while not affecting secretion of the histamine stored in mast cells, which is secreted only when the cells are exposed to specific stimuli $(3,6,34,38-41)$. It has been demonstrated that i.p. injection of $\alpha$-FMH (50-100 mg/kg body wt) reduces HDC activity and histamine content in brain and stomach of rats and mice $(2,38-41)$. Based on this finding, rats in the present experiments were pretreated with $\alpha$-FMH $(100 \mathrm{mg} / \mathrm{kg}$ body wt i.p.) twice daily for $6 \mathrm{~d}$ before surgery and also during the day of the experiment. The inhibitor decreased mucosal HDC activity to $\sim 20 \%$ of the value observed in vehicle-treated animals. The potency of $\alpha$-FMH was further illustrated by its effect on mucosal histamine content (decreased by $37 \%$ ) and histamine output in lymph (decreased by $59 \%$ ). In addition, the marked increases in mucosal HDC activity and histamine content normally observed after $\mathrm{I} / \mathrm{R}$ were completely abolished by $\alpha$-FMH.

Rats pretreated with $\alpha$-FMH exhibited a depressed lymphatic lipid output at $48 \mathrm{~h}$ after I/R insult, which is a time at which lipid output is restored to normal in untreated animals. $\alpha$-FMH per se had no effects on lipid transport at $48 \mathrm{~h}$ in sham-operated rats, which indicates that the drug does not exert a nonspecific action on the mucosa. Furthermore, the I/R rats pretreated with $\alpha$-FMH had a similar amount of radioactive lipid transported in lymph at $24 \mathrm{~h}$ after reperfusion as the I/R rats pretreated with vehicle, indicating that $\alpha$-FMH does not enhance the injury caused by $I / R$. Overall, these data indicate that the recovery of intestinal lipid transport after I/R requires an increase in mucosal HDC activity and histamine content, both of which are prevented by $\alpha$-FMH.

In a previous study (20) we have demonstrated that the reduction in lymphatic lipid transport caused by $I / R$ does not result from inadequate digestion or uptake of the infused lipid, inasmuch as the amount of radioactive lipid remaining in the intestinal lumen is similar in I/R-and sham-operated controls. We have also demonstrated that the decrease in lymphatic lipid output is associated with an increased portal transport of radioactive fatty acid. The latter observation was confirmed in the present study, i.e., I/R rats with decreased lymphatic lipid transport exhibited corresponding increases in portal lipid transport and hepatic lipid content. The increased portal transport of radioactive lipid was also observed in rats pretreated with $\alpha$ FMH, which further supports the view that HDC and histamine play an important role in the repair of the small intestinal epithelium after $\mathbf{I} / \mathrm{R}$.

Another objective of this study was to determine whether the beneficial actions of histamine in the postischemic intestine are mediated by ODC. It is well known that ODC is involved in the repair of the gastrointestinal mucosa after injury (21-23). We have previously demonstrated that mucosal ODC activity is markedly elevated in the postischemic rat intestine (25). In the present study, we observed that the I/R-induced increase in mucosal ODC activity was markedly attenuated by $\alpha-\mathrm{FMH}$ treatment. Watanabe et al. (8) and Batholeyns and Bouclier (10) have reported that the enzyme activities of ODC and HDC do not overlap in vitro and that $\alpha$-FMH exerts no effect on ODC activity in vitro, indicating that $\alpha$-FMH inhibits HDC but not ODC. Thus, our observation that $\alpha$-FMH blunts the I/R-induced increase in intestinal ODC activity suggests that histamine mediates the I/R-induced changes in ODC activity. Such a relationship between histamine and ODC activity is supported by reports that the induction of mucosal HDC activity in the colon by 12-o-tetradecanoylphorbol-13-acetate is associated with an increased mucosal ODC activity (35). Furthermore, histamine has been shown to increase ODC activity in rat brain tissues (42).

In the present experiment, we also measured the DAO activity in the mucosa of postischemic intestine. Histamine is degraded by two catabolizing enzymes, DAO and histamine- $N$ methyltransferase, and both enzymes are present in the rat small intestine (36). DAO activity is mainly located in rat villus tip cells (37), consequently DAO activity has been used as an index of number of mature enterocytes in the small bowel (23, 43). In our study, DAO activity did not change after I/R. This observation indicates that the number of mature enterocytes was not altered in response to I/R. Kusche et al. (44) demonstrated that DAO activity in rabbit small intestine decreased by $60 \%$ after 90 min occlusion of the SMA. Furthermore, they found that the survival of rabbits after $I / R$ was dependent on DAO activity in intestine because inhibition of the enzyme by aminoguanidine markedly reduced the survival period after I/R. They therefore concluded that removal of circulating histamine by DAO protects the small intestine after I/R. Our results and the findings of Kusche et al. (44) are not mutually exclusive and may easily be reconciled by the following explanation. With severe ischemia, circulating histamine released from mast cells is markedly increased and the beneficial actions of the autacoid are outweighed by its undesirable side effects. Thus, DAO activity plays a more important role when small bowel is subjected to severe and/or prolonged periods of ischemia. In contrast, mucosal histamine increases as a result of increased HDC activity with mild ischemia. The increase in histamine concentration is actually beneficial to the animal because it facilitates healing of the injured mucosa. The fact that lymphatic output of RMCP II (a major product of rat mucosal mast cell $[29,31,32])$ did not increase after I/R suggests that the increase in lymphatic histamine after $I / R$ in our study was not a result of the degranulation of mucosal mast cells, i.e., the histamine was derived from non-mast cells.

In conclusion, based upon circumstantial evidence already in the literature and the results of the present study, we propose that histamine and HDC play an important role in the mucosal repair that follows an ischemic insult, and that this effect is probably mediated, at least in part, by ODC.

\section{Acknowledgments}

We appreciate the generous help of Prof. Dean A. Befus, Department of Microbiology, the University of Calgary, for measuring RMCP II. 
We also thank Dr. J. Kollonitsch, Merck Sharp \& Dohme Research Laboratories, Rahway, NJ, for supply of $\alpha$-FMH, and Ms. Laura Gray and Ms. Tomoko Fujimoto for skillful technical assistance.

This research was supported by grants from the National Institute of Health PO1-DK 43785, DK 32288, and DK 33594. Dr. Tso is the recipient of a Research Career Development Award from the National Institute of Health DK 01575.

\section{References}

1. Douglas, W. W. 1985. Histamine and 5-hydroxytryptamine (serotonin) and their antagonists. In The Pharmacological Basis of Therapeutics. 7th ed. A. G. Gilman, L. S. Goodman, T. W. Rall, and F. Murad, editors. Macmillan Publishing Co., New York. 605-638.

2. Sakata, T., K. Fukagawa, K. Ookuma, K. Fujimoto, H. Yoshimatsu, A. Yamatodani, and H. Wada. 1990. Hypothalamic neuronal histamine modulates ad libitum feeding by rats. Brain Res. 537:303-306.

3. Schwartz, J.-C., J.-M. Arrang, M. Garbarg, H. Pollard, and M. Ruat. 1991. Histaminergic transmission in the mammalian brain. Physiol. Rev. 71:1-51.

4. Wada, H., T. Watanabe, Y. K. Maeyama, Y. Taguchi, and H. Hayashi. 1984. Mammalian histidine decarboxylase and its suicide substrate $\alpha$-fluoromethylhistidine. In Chemical and Biological Aspects of Vitamin $B_{6}$ Catalysis.

A. E. Evangelopoulos, editor. Alan R. Liss, Inc., New York. 245-254.

5. Watanabe, T., K. Maeyama, A. Yamatodani, M. Yamada, Y. Kitamura, and $\mathrm{H}$. Wada. 1980. Histidine decarboxylase activities in mutant mice deficien in mast cells. Life Sci. 26:1569-1574.

6. Kahlson, G., and E. Rosengren. 1968. New approaches to physiology of histamine. Physiol. Rev. 48:155-196.

7. Kahlson, G., and E. Rosengren. 1972. Histamine: entering physiology. Experientia (Basel). 28:993-1002.

8. Watanabe, T., Y. Taguchi, K. Sasaki, K. Tsuyama, and Y. Kitamura. 1981. Increase in histidine decarboxylase activity in mouse skin after application of the tumor promoter tetradecanoylphorbol acetate. Biochem. Biophys. Res. Commun. 100:427-432.

9. Ishikawa, E., A. Toki, T. Moriyama, Y. Matsuoka, T. Aikawa, and M. Suda. 1970. A study on the induction of histidine decarboxylase in tumor-bearing rat. J. Biochem. 68:347-358.

10. Bartholeyns, J., and M. Bouclier. 1984. Involvement of histamine in growth of mouse and rat tumors: antitumoral properties of monofluoromethylhistidine, an enzyme-activated irreversible inhibitor of histidine decarboxylase. Cancer Res. 44:639-645.

11. Brandes, L. J., R. P. Boddanovic, M. D. Cawker, and F. S. LaBella. 1987. Histamine and growth: interaction of antiestrogen biding site ligands with novel histamine site that may be associated with calcium channels. Cancer Res. 47:4025-4031.

12. Tilly, B. C., L. G. J. Tertoolen, R. Remorie, A. Ladoux, I. Verlaan, S. W. de Laat, and W. H. Moolenaar. 1990. Histamine as a growth factor and chemoattractant for human carcinoma and melanoma cells: action through $\mathrm{Ca}^{2+}$-mobilizing $\mathrm{H}_{1}$ receptor. J. Cell Biol. 110:1211-1215.

13. Norrby, K. 1985. Evidence of mast-cell histamine being mitogenic in intact tissue. Agents Actions. 16:287-290.

14. Rodsiguez, J., J. Moran, I. Blanco, and A. J. Patel. 1989. Effect of histamine on the development of astroglial cells in culture. Neurochem. Res. 14:693700.

15. Cooke, H. J., P. R. Nemeth, and J. D. Wood. 1984. Histamine action on guinea pig ileal mucosa. Am. J. Physiol. 246:G372-G377.

16. Mortillaro, N. A., D. N. Granger, P. R. Kvietys, G. Rutili, and A. E. Taylor. 1981. Effects of histamine and histamine antagonists on intestinal capillary permeability. Am. J. Physiol. 240:G381-G386.

17. Konturek, S. J., and R. Siebers. 1980. Role of histamine $\mathrm{H}_{1}$ - and $\mathrm{H}_{2}$-receptors in myoelectric activity of small bowel in the dog. Am. J. Physiol. 238:G50G56.

18. Tutton, P. J. M. 1976. The influence of histamine on epithelial cell proliferation in the jejunum of the rat. Clin. Exp. Pharmacol. Physiol. 3:369-373.

19. Granger, D. N. 1988. Role of xanthine oxidase and granulocytes in ischemia-reperfusion injury. Am. J. Physiol. 255:H1269-H1275.

20. Fujimoto, K., V. H. Price, D. N. Granger, R. Specian, S. Bergstedt, and P. Tso. 1991. Effects of ischemia-reperfusion on lipid digestion and absorption in rat intestine. Am. J. Physiol. 260:G595-G602.
21. Johnson, L. R. 1988. Regulation of gastrointestinal mucosal growth. Physiol. Rev. 68:456-502.

22. Wang, J.-Y., and L. R. Johnson. 1991. Polyamines and ornithine decarboxylase during repair of duodenal mucosa after stress in rats. Gastroenterology. 100:333-343.

23. Luk, G. D., L. J. Marton, and S. B. Baylin. 1980. Ornithine decarboxylase is important in intestinal mucosal maturation and recovery from injury in rats. Science (Wash. DC). 210:195-198.

24. Kollonitsch, J., L. M. Perkins, A. A. Patchett, G. A. Doldouras, S. Marburg, D. E. Duggan, A. L. Maycock, and S. D. Aster. 1978. Selective inhibitors of biosynthesis of aminergic neurotransmitters. Nature (Lond.). 274:906-908.

25. Fujimoto, K., D. N. Granger, V. H. Price, and P. Tso. 1991. Ornithine decarboxylase is involved in repair of small intestine after ischemia-reperfusion in rats. Am. J. Physiol. In press.

26. Tso, P., K. L. Buch, J. A. Balint, and J. B. Rodgers. 1982. Maximal lymphatic triglyceride transport rate from the rat small intestine. Am. J. Physiol. 242:G408-G415

27. Yamatodani, A., H. Fukuda, H. Wada, T. Iwaeda, and T. Watanabe. 1985. High-performance liquid chromatographic determination of plasma and brain histamine without previous purification of biological samples: cation-exchange chromatography coupled with post-column derivatization fluorometry. $J$. Chromatogr. 344:115-123.

28. Kusche, J., and W. Lorenz. 1983. Diamine Oxidase. In Methods of Enzymatic Analysis. 3rd ed. Vol. 3. H. U. Bergmeyer, editor. Verlag Chemie GmbH, Weinheim, Germany. 237-250.

29. Miller, H. R. P., R. G. Woodbury, J. F. Huntley, and G. Newlands. 1983. Systemic release of mucosal mast-cell protease in primed rats challenged with Nippistronglus brasiliensis. Immunology. 49:471-479.

30. Winer, B. J. 1971. Statistical Principles in Experimental Design. 2nd ed. McGraw-Hill Book Co., New York. 897 pp.

31. Metcalfe, D. D. 1984. Mast cell mediators with emphasis on intestinal mast cells. Ann. Allergy. 53:563-574.

32. Befus, D., H. Fujimaki, T. D. Lee, and M. Swieter. 1988. Mast cells polymorphisms. Present concepts, future directions. Dig. Dis. Sci. 33(Suppl.):16S-24S.

33. Enerbäck, L. 1981. The gut mucosal mast cell. Monogr. Allergy. 17:222232.

34. Galli, S. J., A. M. Dvorak, and H. F. Dvorak. 1984. Basophils and mast cells: morphologic insights into their biology, secretory pattern, and function. Prog. Allergy. 34:1-141.

35. Sun, Y., and Y. Li. 1988. Induction of ornithine decarboxylase and histidine decarboxylase activities in rat colon mucosa after application of 12-a-tetradecanoylphorbol-13-acetate, sodium deoxycholate and indole. Cancer Lett. 39:77-84.

36. Kim, K. S., B. Backus, M. Harris, and P. Rourke. 1969. Distribution of diamine oxidase and imidazole- $N$-methyltransferase along the gastrointestinal tract. Comp. Biochem. Physiol. 31:137-145.

37. Baylin, S. B., S. A. Stevens, and K. M. M. Shakir. 1978. Association of diamine oxidase and ornithine decarboxylase with maturing cells in rapidly proliferating epithelium. Biochim. Biophys. Acta. 541:415-419.

38. Garbarg, M., G. Barbin, E. Rodergas, and J.-C. Schwartz. 1980. Inhibition of histamine synthesis in brain by $\alpha$-fluoromethylhistidine, new irreversible inhibitor: in vitro and in vivo studies. J. Neurochem. 35:1045-1052.

39. Maeyama, K., T. Watanabe, Y. Taguchi, A. Yamatodani, and H. Wada. 1982. Effect of $\alpha$-fluoromethylhistidine, a suicide inhibitor of histidine decarboxylase, on histamine levels in mouse tissues. Biochem. Pharmacol. 31:2367-2370.

40. Bouclier, M., J. Jung, and F. Gerhart. 1983. Effects of prolonged inhibition of histidine decarboxylase on tissue histamine concentrations. Experientia (Basel). 39:1303-1305.

41. Fujimoto, K., T. Sakata, K. Ookuma, M. Kurokawa, A. Yamatodani, and H. Wada. 1990. Hypothalamic histamine modulates adaptive behavior of rats at high environmental temperature. Experientia (Basel). 46:283-285.

42. Morris, G., F. J. Seidler, and T. A. Slotkin. 1983. Stimulation of ornithine decarboxylase by histamine or norepinephrine in brain regions of the developing rat: evidence for biogenic amine as trophic agents in neonatal brain development. Life Sci. 32:1565-1571.

43. Luk, G. D., T. M. Bayless, and S. B. Baylin. 1980. Diamine oxidase (histaminase), a circulating marker for rat intestinal mucosal maturation and integrity. J. Clin. Invest. 66:66-70.

44. Kusche, J., W. Lorenz, C.-D. Stahlknecht, H. Richter, R. Hesterberg, A. Schmal, E. Hinterlang, D. Weber, and C. Ohmann. 1981. Intestinal diamine oxidase and histamine release in rabbit mesenteric ischemia. Gastroenterology. 80:980-987. 